\title{
Research on logistics efficiency evaluation and promotion strategy of the "Belt and Road" core economic belt
}

\author{
Tingting Qu ${ }^{1}$, Qing $\mathrm{Li}^{2}$ \\ ${ }^{1}$ Institute of Management, Dalian Polytechnic University, No. 1st Qinggongyuan, Ganjingzi,, \\ Dalian, China \\ ${ }^{2}$ Institude of Management, Dalian Polytechnic University, No. 1st Qinggongyuan, Ganjingzi,, \\ Dalian, China \\ qing625@163.com
}

Keywords: the "Belt and Road" core economic belt, Logistics efficiency, Super-efficient SBM model

Abstract: Based on the method of super-efficient SBM model, this paper analyzed the logistics efficiency of the "Belt and Road" core economic belt. On the basis of the comprehensive efficiency, technical efficiency and scale efficiency, meanwhile compared the amount of input and output slack, further studied the current situation of logistics efficiency in the five northwestern provinces, and combined with data to analyze their respective strengths and weaknesses. Finally, through evaluated relevant data, then give suggestions for improving logistics efficiency in the five northwestern provinces, and further realize the overall goal of logistics development in the core belt of "The Belt and Road".

\section{Introduction}

Promoting the construction of the "Belt and Road" is a major initiative for the Chinese government under the background of global economic and political. It has an inter-generational significance for the economic prosperity and development of all regions along the entire line. The five northwestern provinces (i.e. Shanxi, Gansu, Ningxia, Qinghai, Xinjiang) are the core areas of the Silk Road Economic Belt in the "Belt and Road". They have been the key poverty alleviation areas of the country for many years due to various geographical factors. The introduction of the Silk Road Economic Belt has brought unprecedented opportunities to the five northwestern provinces. The East Asia Economic Circle and the favorable conditions of the European Economic Circle in the West not only cover a huge market development space, but also make it becomes "The largest and most promising economic corridor in the world." Therefore, compared with the poverty alleviation policy such as the Western Development, the "Belt and Road" is a good medicine for the economic development of the northwest. It not only provides a steady stream of benefits to the five northwestern provinces, but also recognizes the important economic status of the five northwestern provinces. And development potential will also promote the formation of new trade and logistics channels. With the increasing two-way trade activities between neighboring countries and China, it is particularly important to study the efficiency of the logistics industry in the core economic zone, 
also useful for plan, manage and implement the development of the logistics industry, accelerate the prosperity of the entire core economic belt. As the central area of the entire Silk Road Economic Belt, which plays a role in the east and west, connecting the north and the south, this paper will analyze and evaluate the logistics efficiency of the five provinces of Shanxi, Gansu, Ningxia, Qinghai and Xinjiang in 2007-2016. Suggest.

\section{Research Foundation and Method}

\subsection{Research Foundation}

Through in-depth investigation and extensive analysis of this research at home and abroad, the current research results on logistics efficiency generally have the following aspects.

Firstly, distinguish by research methods. Research methods on logistics efficiency use more quantitative methods, including stochastic frontier method (SFA), data enveloping method (DEA), principal component analysis, etc., among which the DEA method is more widely used. Liu Yuan specifically analyzed the superiority of the DEA method in the efficiency of logistics enterprises (Yuan, 2001). Shuai Bin and Du Wen combined the DEA and other methods to analyze the logistics efficiency (Bin, 2006). Rita Markovis used a new DEA-PCA method to evaluate the logistics efficiency of 29 European countries (Rita, 2014). Lin Tan and Wang Ling use SFA to estimate the productivity of the logistics industry (Tan, 2008).

Although the DEA method has a great contribution in the study of logistics efficiency, it cannot calculate the slack variables of input and output, and cannot clearly see the input redundancy and output shortage. Therefore, this paper will adopt the super-efficient SBM model. It can more fully reflect the essence of regional logistics efficiency measurement (Yuhong, 2017).

Second, the efficiency of different ranges of logistics industry is differentiated. It is basically the study of the efficiency of logistics enterprises, the efficiency research of the internal industry of logistics industry, and the research of logistics efficiency in the region. $\mathrm{Xu} \mathrm{Xin}$ and other studies have analyzed the logistics efficiency of multinational logistics companies. Skinner uses the DEA model to analyze the logistics efficiency of third-party logistics companies (Xin, 2014). Martinez et al. evaluated the logistics efficiency of the main ports in Spain (Martinez, 1999). Yao Juan Zhuang Yuliang and others have made an evaluation of the overall logistics industry efficiency in China (Juan, 2013).Wang Qinmei and Tan Cuiyi analyzed the logistics efficiency of Xi'an in 20032012(Qinmei, 2013). Wang Lei and Xue Guoliang used the C2R and GS2 models of DEA analysis to analyze the logistics industry efficiency in Xinjiang from 2006 to 2012(Lei, 2014).

At present, the Silk Road Economic Belt is mainly a long-term study in a single region or a study in a certain region in a multi-region, but lacks data analysis for a long period of time in the western region.

It can be seen that the current research results on logistics efficiency are relatively mature, providing strong support for subsequent research, but there are still some shortcomings in the existing research results. Therefore, this paper will focus on the research and analysis of the five provinces in the northwestern region. Through the method of super-efficient SBM, will mainly analyzes the following aspects: (1) Defining the input and output factors, establishing an evaluation system, and determining Input-output data of the five northwestern provinces from 2007 to 2016. (2) Applying the super-efficient SBM model, the overall and separate technical efficiency, pure technical efficiency and scale efficiency of the five northwestern provinces are obtained. (3) Further analyze the impact of slack variables on input and output factors, give strategies for improving logistics efficiency, and provide relevant suggestions for developing the new channels in Northwest China. 


\subsection{Description of super efficiency SBM model}

In 2001, Tone proposed a non-radial approach to the efficiency of simultaneous relaxation variables, the SBM model. Since the traditional CCR or BBC model reevaluation process may occur multiple effective units (Tao, 2017), this is for efficiency evaluation and the comparison has certain limitations. However, the super-efficient SBM model not only solves the problem of sorting multiple effective units, but also considers the slack variables, which has a good reference value for further analysis of input-output factors (Yuhong, 2017). At the same time, in 2002, Tone proposed an ultra-efficient SBM model to solve the problem of distinguishing and sorting when multiple decision units have efficiency values of 1.

Based on the above factors, the super-efficiency SBM model is constructed as follows:

Suppose there are “m” input factors, "s" output factors, and a linear programming equation:

$$
\begin{gathered}
\min _{\mathrm{SE}}=\frac{1+\frac{1}{\mathrm{~m}} \sum_{\mathrm{i}=1}^{\mathrm{m}} \mathrm{s}_{\mathrm{i}}^{-} / \mathrm{x}_{\mathrm{ik}}}{1-\frac{1}{\mathrm{~s}} \sum_{\mathrm{i}=1}^{\mathrm{s}} \mathrm{s}_{\mathrm{r}}^{+} / \mathrm{y}_{\mathrm{rk}}} \\
\text { s.t. } \sum_{\mathrm{j}=1, \mathrm{j} \neq \mathrm{k}}^{\mathrm{n}} \mathrm{x}_{\mathrm{ij}} \lambda_{\mathrm{j}}-\mathrm{s}_{\mathrm{i}}^{-} \ll \mathrm{x}_{\mathrm{ik}} \\
\sum_{\mathrm{j}=1, \mathrm{j} \neq \mathrm{k}}^{\mathrm{n}} \mathrm{y}_{\mathrm{rj}} \lambda_{\mathrm{j}}+\mathrm{s}_{\mathrm{r}}^{+} \gg \mathrm{y}_{\mathrm{rk}} \\
\lambda, \mathrm{s}^{-}, \mathrm{s}^{+} \gg 0 \\
\mathrm{i}=1,2, \ldots \mathrm{m} ; \mathrm{r}=1,2, \ldots \mathrm{q} ; \mathrm{j}=1,2, \ldots \mathrm{n}(\mathrm{j} \neq \mathrm{k})
\end{gathered}
$$

Where $\rho$ is the efficiency value; $\lambda$ is the envelope multiplier; $x_{k}$ and $y_{k}$ are distinctly the input vector and output vector of $\mathrm{DMU}_{\mathrm{k}}, \mathrm{x}_{\mathrm{k}}$ and $\mathrm{y}_{\mathrm{k}}$ are the $\mathrm{i}$-th input element and $\mathrm{r}$-th output element, respectively, and $s_{i}^{-}$is slack Input, $s_{r}^{+}$is a slack output. For the unit to be evaluated $\mathrm{DMU}_{\mathrm{k}}, \rho$ is a super efficiency value and may be greater than 1(Tao, 2017).

\section{Analysis of logistics efficiency and slack of core economic belt}

\subsection{Data selection}

First of all, it is necessary to determine the relevant data of logistics efficiency analysis, but the research finds that there is no classification of "logistics industry" in China's current industry classification. At the same time, it is also the same in the whole world classification, so considering modern logistics. The industry's characteristics are a composite service industry that combines transportation, warehousing, post and telecommunications industries (Yuhong, 2017). According to the China Statistical Yearbook, the added value of the transportation, warehousing and postal industries accounted for more than $80 \%$ of the added value of the logistics industry in each year from 2007 to 2016. Therefore, the data of the transportation, warehousing and postal industries are similar to the development level of logistics industrial.

At the same time, combined with existing research and considering the various factors such as the reliability and availability of data, the following input-output was finally adopted as the logistics efficiency for research. 
Table 1 Logistics input and output indicators

\begin{tabular}{|c|c|}
\hline Indicator type & Indicator content \\
\hline Input indicators & $\begin{array}{c}\text { I---Total Investment in Fixed } \\
\text { Assets(100 million yuan) }\end{array}$ \\
\cline { 2 - 2 } & $\begin{array}{c}\text { E---Number of employees in } \\
\text { logistics industry(10000 persons) }\end{array}$ \\
\hline Output indicators & $\begin{array}{c}\text { V---Added value of logistics } \\
\text { industry(100 million yuan) }\end{array}$ \\
\cline { 2 - 2 } & $\begin{array}{c}\text { T---Freight Ton-Kilometers(100 } \\
\text { million ton-km) }\end{array}$ \\
\hline
\end{tabular}

Finally, the relevant data samples of the five northwestern provinces of 2007-2016 were obtained. Descriptive statistics are shown in the table 2.

Table 2 Descriptive statistics of sample data

\begin{tabular}{|c|c|c|c|c|}
\hline Indicators & $\begin{array}{c}\text { Numbers } \\
\text { of } \\
\text { samples }\end{array}$ & Max & Min & Average \\
\hline I & 50.000 & 1584.620 & 48.900 & 2226.416 \\
\hline E & 50.000 & 27.860 & 3.223 & 56.990 \\
\hline V & 50.000 & 1911.300 & 40.590 & 1372.832 \\
\hline T & 50.000 & 3521.460 & 176.300 & 7442.678 \\
\hline
\end{tabular}

(Noted: I---Total Investment in Fixed Assets (100 million yuan) E---Number of employees in logistics industry (10000 persons) V---Added value of logistics industry (100 million yuan) T--Freight Ton-Kilometers(100 million ton-km))

\subsection{Calculation result}

With the DEA SOLVER software, from the output orientation, the ultra-efficient SBM model is used to calculate the logistics industry efficiency of the five northwestern provinces in 2007-2016.

\subsubsection{Logistics efficiency year after year data}

Table 3 shows, according to the sum of the data of the five northwestern provinces, the average technical efficiency of logistics efficiency in the five northwestern provinces is calculated to be 0.92 . However, the annual comprehensive efficiency of 2013-2016 can be found to be lower than the average. Most of the 10-year pure technical efficiency is relatively close to 1 , and exceeded 1 , so it is mainly because the scale efficiency is too low lead to the overall efficiency is too low. In addition, it can be seen that 2012 is the demarcation point, and its comprehensive technical efficiency is relatively high. At the same time, in 2009-2011, which is before 2012, the scale efficiency was significantly higher than the pure technical efficiency. In general, it also conforms to the situation of the five northwestern provinces. In the early stage of 2009-2011, it was a growth stage, which the infrastructure investment in the logistics industry was not perfect. It was a mature stage in 2012, and the input-output level reached its peak in 2013-2016. There has been a decline phase, indicating that the fixed assets and employees are redundant, and the ideal cargo turnover and logistics industry added value have not been fully achieved. 
Table 3 Total logistics efficiency and decomposition of five provinces in northwest China from 2007 to 2016

\begin{tabular}{|c|c|c|c|}
\hline DMU & $\begin{array}{c}\text { Comprehensive } \\
\text { efficiency }\end{array}$ & $\begin{array}{c}\text { Technical } \\
\text { efficiency }\end{array}$ & $\begin{array}{c}\text { Scale } \\
\text { efficiency }\end{array}$ \\
\hline 2007 & 1.034 & 0.953 & 1.086 \\
\hline 2008 & 1.123 & 1.123 & 1.000 \\
\hline 2009 & 0.858 & 0.887 & 0.966 \\
\hline 2010 & 0.812 & 0.840 & 0.966 \\
\hline 2011 & 0.900 & 0.947 & 0.949 \\
\hline 2012 & 1.336 & 1.033 & 1.293 \\
\hline 2013 & 0.789 & 0.963 & 0.820 \\
\hline 2014 & 0.773 & 1.029 & 0.751 \\
\hline 2015 & 0.776 & 0.974 & 0.797 \\
\hline 2016 & 0.798 & 1.033 & 0.772 \\
\hline Average & 0.920 & 0.978 & 0.940 \\
\hline
\end{tabular}

Table 4 From 2007 to 2016, provincial logistics efficiency and decomposition

\begin{tabular}{|c|c|c|c|c|c|c|c|c|c|c|c|c|c|c|c|}
\hline \multirow[b]{2}{*}{ Year } & \multicolumn{5}{|c|}{ Comprehensive efficiency } & \multicolumn{5}{|c|}{ Technical efficiency } & \multicolumn{5}{|c|}{ Scale efficiency } \\
\hline & SX & GS & $\mathrm{QH}$ & NX & XJ & SX & GS & $\mathrm{QH}$ & NX & XJ & SX & GS & $\mathrm{QH}$ & NX & XJ \\
\hline 2007 & 0.806 & 0.889 & 0.708 & 0.706 & 1.209 & 0.983 & 0.977 & 0.973 & 0.953 & 1.000 & 0.806 & 0.889 & 0.708 & 0.706 & 1.209 \\
\hline 2008 & 1.096 & 1.190 & 0.851 & 1.040 & 1.058 & 1.168 & 1.190 & 1.057 & 1.397 & 1.007 & 0.938 & 1.000 & 0.851 & 0.744 & 1.058 \\
\hline 2009 & 0.842 & 0.873 & 0.798 & 0.803 & 0.797 & 0.864 & 0.920 & 0.832 & 0.831 & 0.802 & 0.975 & 0.949 & 0.959 & 0.966 & 0.993 \\
\hline 2010 & 0.781 & 0.843 & 0.897 & 0.767 & 0.739 & 0.805 & 0.879 & 0.930 & 0.845 & 0.743 & 0.971 & 0.959 & 0.965 & 0.908 & 0.995 \\
\hline 2011 & 0.835 & 0.902 & 1.202 & 0.946 & 0.836 & 0.866 & 0.962 & 1.220 & 0.953 & 0.879 & 0.964 & 0.938 & 0.985 & 0.992 & 0.952 \\
\hline 2012 & 1.376 & 1.323 & 1.252 & 1.192 & 1.178 & 1.054 & 1.023 & 1.004 & 1.281 & 1.323 & 1.376 & 1.323 & 1.252 & 0.930 & 0.890 \\
\hline 2013 & 0.871 & 0.746 & 0.702 & 0.798 & 0.842 & 0.943 & 0.914 & 0.923 & 1.001 & 1.025 & 0.923 & 0.816 & 0.761 & 0.797 & 0.822 \\
\hline 2014 & 0.875 & 0.805 & 0.857 & 0.802 & 0.889 & 1.063 & 1.032 & 1.001 & 0.911 & 1.021 & 0.823 & 0.780 & 0.856 & 0.881 & 0.870 \\
\hline 2015 & 0.702 & 0.746 & 0.796 & 0.834 & 0.953 & 0.961 & 0.901 & 1.033 & 0.922 & 0.963 & 0.731 & 0.828 & 0.770 & 0.904 & 0.989 \\
\hline 2016 & 0.732 & 0.716 & 1.018 & 1.009 & 1.051 & 1.047 & 0.884 & 1.049 & 1.017 & 1.070 & 0.699 & 0.809 & 0.971 & 0.992 & 0.982 \\
\hline Average & 0.892 & 0.903 & 0.908 & 0.890 & 0.955 & 0.975 & 0.968 & 1.002 & 1.011 & 0.983 & 0.921 & 0.929 & 0.908 & 0.882 & 0.976 \\
\hline
\end{tabular}

As shown the data in Table 4, the average efficiency of the comprehensive efficiency, the logistics efficiency of Xinjiang Province is relatively high, the difference between Qinghai, Gansu, and Shanxi is not large, and Ningxia is slightly lower. The trend of the provinces in 2009-2011 is also basically consistent with the overall situation. The scale efficiency is greater than the pure technical efficiency, so it eventually leads to a relatively low overall efficiency. In terms of the overall trend, 2012 is the peak point of input and output for all provinces, but the three provinces of Xinjiang, Ningxia, Qinghai, have slowly increased after a slight decline in 2013, their pure technical efficiency has remained greater than 1 , and significantly larger than the scale. effectiveness. Therefore, it is not difficult to find out that in 2013, after the relevant policies of the "Silk Road Economic Belt" were put forward, the investment of infrastructure in the western region was significantly increased. However, due to the actual conditions of the provinces, the scale efficiency did not reach the same level. Therefore, rational allocation of resources for the actual situation of each province will have a significant effect on the improvement of logistics efficiency.

\subsubsection{Relaxation variable analysis}

Tables 5 and 6 show the overall and separate relaxation also the relaxation ratios for the five northwestern provinces from 2007 to 2016, the relaxation ratio = slack/original input. 
In Table 5, except 2007, 2012 and 2012 inputs achieved the desired output, the remaining years have more or less insufficient output, whether it is the value added of the logistics industry or the turnover of goods. None of them achieved the expected results. At the same time, it was found that the shortage of cargo turnover was more obvious in the slack ratio. Therefore, it also showed that the basic transportation facilities in the northwest region were not fully utilized, and the cargo turnover needs to be improved.

Table 5 The slack quantity and slack proportion of the whole logistics industry in five provinces in northwest China

\begin{tabular}{|r|l|c|c|c|c|}
\hline \multirow{2}{*}{ YEAR } & \multirow{2}{*}{ SCORE } & \multicolumn{2}{|c|}{ V } & \multicolumn{2}{c|}{ T } \\
\cline { 3 - 6 } & & Relaxation & $\begin{array}{c}\text { Relaxation } \\
\text { ratio }\end{array}$ & Relaxation & $\begin{array}{c}\text { Relaxation } \\
\text { ratio }\end{array}$ \\
\hline 2007 & 1.034 & --- & --- & --- & --- \\
\hline 2008 & 1.123 & --- & --- & --- & --- \\
\hline 2009 & 0.858 & 162.846 & $16.12 \%$ & 1060.651 & $17.08 \%$ \\
\hline 2010 & 0.812 & 275.469 & $24.36 \%$ & 1500.818 & $21.99 \%$ \\
\hline 2011 & 0.900 & 132.087 & $9.92 \%$ & 961.821 & $12.40 \%$ \\
\hline 2012 & 1.336 & --- & --- & --- & --- \\
\hline 2013 & 0.789 & 405.741 & $26.38 \%$ & 2347.904 & $27.04 \%$ \\
\hline 2014 & 0.773 & 463.769 & $27.00 \%$ & 2949.224 & $31.84 \%$ \\
\hline 2015 & 0.776 & 319.303 & $17.59 \%$ & 3423.094 & $40.15 \%$ \\
\hline 2016 & 0.798 & 239.296 & $12.52 \%$ & 3324.830 & $38.15 \%$ \\
\hline
\end{tabular}

Table 6 Save the slack and slack proportion of logistics industry

\begin{tabular}{|c|c|c|c|c|c|c|c|c|c|c|}
\hline \multirow[b]{2}{*}{ DMU } & \multicolumn{2}{|c|}{ SX---K } & \multicolumn{2}{|c|}{ GS---K } & \multicolumn{2}{|c|}{ QH---K } & \multicolumn{2}{|c|}{ NX---K } & \multicolumn{2}{|c|}{ XJ---K } \\
\hline & Relaxation & $\begin{array}{l}\text { Relaxation } \\
\text { ratio }\end{array}$ & Relaxation & $\begin{array}{c}\text { Relaxation } \\
\text { ratio }\end{array}$ & Relaxation & $\begin{array}{l}\text { Relaxation } \\
\text { ratio } \\
\end{array}$ & Relaxation & $\begin{array}{l}\text { Relaxation } \\
\text { ratio }\end{array}$ & Relaxation & $\begin{array}{c}\text { Relaxation } \\
\text { ratio } \\
\end{array}$ \\
\hline 2007 & 567.699 & $47.66 \%$ & 256.578 & $22.31 \%$ & 134.185 & $76.11 \%$ & 168.452 & $57.77 \%$ & --- & --- \\
\hline 2008 & --- & --- & --- & --- & 42.591 & $12.69 \%$ & --- & --- & --- & --- \\
\hline 2009 & 393.854 & $17.75 \%$ & 227.545 & $14.05 \%$ & 86.467 & $23.74 \%$ & 96.832 & $12.90 \%$ & 132.443 & $10.55 \%$ \\
\hline 2010 & 641.978 & $26.05 \%$ & 284.669 & $16.14 \%$ & 60.453 & $14.40 \%$ & 227.963 & $27.85 \%$ & 213.691 & $15.73 \%$ \\
\hline 2011 & 546.086 & $19.33 \%$ & 245.592 & $12.06 \%$ & --- & --- & 59.704 & $6.40 \%$ & 120.076 & $8.14 \%$ \\
\hline 2012 & --- & --- & --- & --- & --- & --- & --- & --- & --- & --- \\
\hline 2013 & 472.793 & $14.77 \%$ & 513.940 & $21.76 \%$ & 250.814 & $55.50 \%$ & 335.096 & $38.38 \%$ & 326.046 & $18.15 \%$ \\
\hline 2014 & 538.949 & $15.30 \%$ & 302.353 & $12.02 \%$ & 134.231 & $26.48 \%$ & 338.651 & $40.47 \%$ & 385.642 & $20.50 \%$ \\
\hline 2015 & 1678.161 & $51.42 \%$ & 614.899 & $27.63 \%$ & 224.861 & $50.46 \%$ & 302.547 & $37.03 \%$ & 175.533 & $9.90 \%$ \\
\hline 2016 & 1554.657 & $45.13 \%$ & 735.245 & $33.88 \%$ & --- & --- & --- & --- & --- & --- \\
\hline \multirow[b]{2}{*}{ DMU } & \multicolumn{2}{|c|}{ SX---V } & \multicolumn{2}{|c|}{ GS---V } & \multicolumn{2}{|c|}{ QH---V } & \multicolumn{2}{|c|}{ NX---V } & \multicolumn{2}{|c|}{ XI---V } \\
\hline & Relaxation & $\begin{array}{l}\text { Relaxation } \\
\text { ratio }\end{array}$ & Relaxation & $\begin{array}{c}\text { Relaxation } \\
\text { ratio }\end{array}$ & Relaxation & $\begin{array}{l}\text { Relaxation } \\
\text { ratio }\end{array}$ & Relaxation & $\begin{array}{l}\text { Relaxation } \\
\text { ratio } \\
\end{array}$ & Relaxation & $\begin{array}{c}\text { Relaxation } \\
\text { ratio }\end{array}$ \\
\hline 2007 & 2.747 & $0.35 \%$ & 4.929 & $2.72 \%$ & 2.518 & $6.20 \%$ & 17.290 & $25.60 \%$ & --- & --- \\
\hline 2008 & --- & --- & --- & -- & 9.547 & $22.22 \%$ & --- & --- & --- & --- \\
\hline 2009 & 198.544 & $19.66 \%$ & 32.136 & $15.04 \%$ & 13.246 & $26.86 \%$ & 41.426 & $36.10 \%$ & 84.689 & $40.50 \%$ \\
\hline 2010 & 338.256 & $29.92 \%$ & 47.669 & $20.98 \%$ & 5.177 & $8.45 \%$ & 47.792 & $32.92 \%$ & 122.159 & $54.91 \%$ \\
\hline 2011 & 270.356 & $20.31 \%$ & 27.184 & $9.70 \%$ & --- & --- & 8.930 & $5.13 \%$ & 79.789 & $31.08 \%$ \\
\hline 2012 & --- & --- & --- & --- & --- & --- & --- & --- & --- & --- \\
\hline 2013 & 230.186 & $14.97 \%$ & 123.736 & $46.31 \%$ & 21.796 & $29.36 \%$ & 24.355 & $12.28 \%$ & 74.596 & $19.28 \%$ \\
\hline 2014 & 227.325 & $13.24 \%$ & 102.290 & $36.44 \%$ & 5.637 & $6.90 \%$ & 17.805 & $8.95 \%$ & 22.008 & $4.58 \%$ \\
\hline 2015 & 605.186 & $33.34 \%$ & 111.481 & $40.59 \%$ & 0.774 & $0.86 \%$ & 5.737 & $2.86 \%$ & --- & --- \\
\hline 2016 & 537.179 & $28.11 \%$ & 123.660 & $45.59 \%$ & --- & --- & --- & --- & --- & --- \\
\hline
\end{tabular}

Through Table 6, we can more clearly see the output of the five provinces in the past decades. First of all, Xinjiang's output situation is relatively stable. In 2009 and 2010, the logistics industry has a higher rate of added value. It can be seen that Xinjiang has some achievements in the development of the logistics industry, but it still needs to pay attention to the rationality of resources configuration, while ensuring the added value of the goods, and thus ensuring the value of the property to promote the overall development of Xinjiang. Secondly, the slack rate of cargo turnover 
in Qinghai Province is relatively high in the five provinces, also exceeding 50\% for many times. The geographical position of Qinghai Province is relatively inferior. It is necessary to strengthen the infrastructure construction, and improve the cargo transportation volume meanwhile ensuring quality and efficiency. In addition, Shanxi, Gansu and Ningxia all have insufficient output, and the cargo turnover and the added value of the logistics industry have not reached the expected level, indicating that there is a significant mismatch between the input and output of the overall development of the logistics industry, lead to the magnitude did not reach the expected return.

\section{Evaluation and summary}

This paper takes the logistics efficiency of the Belt and Belt Core Economic Belt as the research object, and calculates the logistics efficiency of the five northwestern provinces through the superefficient SBM model.

(1) The average logistics efficiency of the five northwestern provinces in 2007-2016 is 0.92, but the logistics efficiency in recent years has been significantly lower than the average, showing the bottleneck period in the development of the logistics industry, which pure technology has generally increased significantly, the average value is also close to 1 , indicating that the logistics efficiency of the core economic zone is relatively stable and the level is high. The main reason is the development of the logistics industry, the advancement of science and technology, and the highquality talents also make a significant impact for the efficiency. The economic belt effect of the Silk Road began to emerge gradually. The trend of scale efficiency is basically consistent with the comprehensive efficiency, and the pure technical efficiency is higher than the scale efficiency obviously. Therefore, scale efficiency is the main factor that restricts the overall efficiency. The logistics scale of the economic belt is too small, resulting in low logistics efficiency.

In the respective logistics efficiency results of the five provinces, the efficiency of Xinjiang Province is relatively stable, and the average value is also the highest among the five provinces. The efficiency fluctuation of Shanxi Province is large, and the efficiency of the five provinces in the 2012 is extremely high then Sudden reduction. In terms of average efficiency, the average value of Xinjiang in the period of 2007-2016 is relatively high in the five provinces, while the Ningxia contrast is slightly insufficient. At the same time, the pure technical efficiency of Xinjiang Province has reached 1 , or even more, that shows Xinjiang's resource allocation is relatively reasonable, and the input part has basically reached full utilization and achieved ideal output. The scale of the logistics industry is also relatively scientific and the degree of specialization is quite high. The pure technical efficiency of Ningxia has been ideal, but the scale efficiency is relatively poor, and then inhibit the comprehensive efficiency. Therefore, controlling the scale of the logistics industry, rationally allocating resources, and improving the professionalization of the logistics industry have become the primary goals of the development of the logistics industry in Ningxia. The comprehensive efficiency of Gansu and Qinghai provinces is basically similar, but the pure technical efficiency and scale efficiency are completely opposite. Gansu has an advantage in scale efficiency and Qinghai has higher pure technical efficiency, so it is not difficult to find the focus and relative weakness of the two provinces. In addition, before 2012, the five provinces were all affected by pure technical factors, and after achieving the best output in 2012, scale efficiency became the main influencing factor of overall efficiency.

(2) The slack ratio can be seen that the overall cargo turnover is insufficient, the geographical environment of the five northwestern provinces is not dominant, and its economic base is backward relative to the eastern region. Its cargo transportation is mainly based on roads and railways and this is also predictable situation. In the five provinces, the lack of output of cargo turnover is mainly manifested in Qinghai, Shaanxi and Gansu. Xinjiang's output in both cargo turnover and logistics 
industry added value performed well, which also matched its high logistics efficiency. Although Ningxia's logistics efficiency is slightly insufficient, its output gap is not very large.

\section{Suggestions on logistics efficiency improvement}

The "Belt and Road" Initiative is a major national strategy. Its development and construction need to be supported by an efficient logistics industry. Therefore, in order to further improve the overall logistics efficiency of the core economic zone and promote coordination and cooperation among provinces and countries. The following improvement strategies are given to the development of the logistics industry in the core economic zone:

\subsection{Reasonable resource allocation, improve resource utilization and save logistics costs.}

According to the "13th Five-Year Plan" and macro management, the specific objectives of developing the logistics industry need to combine the actual situation of the five northwestern provinces, expand the logistics scale and optimize the allocation of logistics resources so that they can achieve optimal output with established inputs. Accelerate the integration of logistics resources such as roads and railways, optimize the regional layout, improve the supply chain system, provide value-added services, share logistics resources, save logistics costs, and ultimately improve logistics efficiency.

\subsection{Strengthen railway construction in inland areas and promote international trade.}

Promoting railway construction comprehensively, connect various countries and regions on the new Asia-Europe continent through a strong railway network, and form strategic partnerships with the investment of cooperative cities along the Belt and Road. With the support of policies, rationally plan personalized logistics solutions, innovate in many aspects such as service and price. Finally, it promotes international trade and truly realizes the double increase of cargo turnover and the added value of the logistics industry.

\subsection{Establish an industrial cluster.}

Through the promotion of the Belt and Road Initiative, it is inevitable to lead the cluster development of the logistics industry, attract a large number of logistics enterprises to gather in the core economy, and truly realize the industrial cluster. For example, in Xi'an, Shanxi, Xinjiang and other places to form a logistics center, then improve the efficiency of the "core area" logistics industry. At the same time, with the premise of promoting industrialization, informationization and modernization, the logistics industry will be agglomerated, which not only enables the sharing of resources among logistics enterprises, but also achieves the effect of economies of scale. It also enhances the logistics efficiency and promotes the logistics industry development of the entire northwest region.

\subsection{Improve the core competitiveness of logistics enterprises.}

Cultivate competitive logistics leading enterprises, change the logistics enterprises small, scattered, chaotic, single logistics behavior, non-uniform service standards, etc., improve the socialization and specialization of the logistics industry, to improve the economies of scale and logistics efficiency of the new Silk Road Economic Belt. 


\subsection{Focus on the logistics advantages of each region.}

Based on the actual situation of each province, effectively play the role of different provinces in the economic belt industry layout, and promote the formation of synergy among the provinces in logistics development. The central city of the new Silk Road Economic Belt needs to take advantage of location. For example, as the core of the Silk Road economic belt, Xinjiang should give full play to its location advantages, vigorously develop advanced logistics information management systems, and improve the logistics transportation distance caused by the economic dispersion of the oasis through high-level cloud computing. Save logistics costs, reduce the barrier between logistics companies, and ultimately improve the efficiency of the logistics industry (Qinmei, 2017). Qinghai Province should pay attention to the development of multimodal transport, connect roads, railways and air transport, and become an integrated logistics network along the "Belt and Road" to improve the turnover of goods (Wen, 2016). Although Ningxia's geographical location is not a seaport or a border, it is an important fulcrum for the construction of the "Silk Silk Road". It should focus on its advantageous projects and form an international aviation logistics center, making Ningxia a transit hub for domestic aviation. Lanzhou, the grand event in Gansu, is the center of the northwest railway and highway network. It can become the core area of the entire Eurasian Continental Bridge and directly connect with the traffic in southwestern and northwestern China. Therefore, it is necessary to make full use of the advantages of Lanzhou's national comprehensive transportation hub and promote its Road construction is of great benefit to the development of multimodal transport of passengers and freight throughout the Northwest Territories (Lei, 2016). Xi'an in Shanxi Province has the geographical advantage of connecting the east and the west and connecting the north and the south. Therefore, the government should improve the basic facilities, speed up the upgrading of the line, and provide the basic conditions for the development of the entire core economic belt.

\subsection{Cultivate specialized logistics talents and attach importance to the Internet system.}

Improve the quality of logistics talents, increase the number of high-end talents and contribute to the logistics industry. In the context of the rapid development of the Internet today, modern logistics companies must also follow the new business model. The government should increase investment in information technology such as e-commerce, cross-border e-commerce, and cloud platforms to achieve various provinces and regions along the "Belt and Road". The national logistics platform realizes data exchange. At the same time, logistics enterprises also need to strengthen and improve their own information management technology, continue to innovate, promote the infiltration of informationization into all aspects of enterprises, and improve logistics efficiency.

Finally, driven by the "Belt and Road", the five northwestern provinces should develop together, narrow the gap in the logistics industry, adhere to the spirit of the Silk Road, and work together to improve logistics efficiency, thus achieving "policy communication, road connectivity, smooth trade, currency circulation, and people's hearts”.

\section{References}

[1] Tao, Liu, Jingjuan, Huo, 2017. The Evaluation on the Logistics Efficiency of Henan Province Based on Super Efficiency SBM Model [J], Logistics Sci-Tech. 40(04), pp.114-118.

[2] Qinmei, Wang, Ying, Jing, 2017. Evaluation of logistics efficiency of Xinjiang in "core area" of Silk Road economic belt [J], Gansu Theory Research. (06), pp.104-109.

[3] Yuhong, Wang, Qi, Liu, 2017. Study on logistics efficiency measurement of Yangtze River economic belt based on Super-SBM model [J], East China Economic Management. (06), pp.104-109.

[4] Wen, Qin, 2016. An empirical study on logistics efficiency and its influencing factors in qinghai province [J], 
Qinghai Social Sciences. (01), pp.99-104.

[5] Lei, Li, Na, Chen, 2016. Research on logistics development in gansu province under the background of "One Belt And One Road" strategy $[\mathrm{J}]$,

[6] China Economic \& Trade Herald. (05), pp.27-28.

[7] Yuan, Liu, 2001. Efficiency evaluation of enterprise logistics system based on DEA method [J], Economic Survey. (05), pp.54-55.

[8] Bin, Shuai, Wen, Du, 2006. DEA/PCA Evaluation of the Structures of Logistics Industry [J], Journal of Southwest Jiaotong University. (05), pp.599-602.

[9] Rita, Markovits, 2014. Assessing the logistics effciency of European countries by using the DEA-PC methodology [J], Transport. 29(2), pp.137-145.

[10] Tan, Lin, Ling, Wang, 2008. Analysis of regional logistics efficiency in China based on SFA method [J], Port Economy. (12), pp.46-49.

[11] Xin, Xu, Yanmin, Zhang, 2014. Study on the choice of logistics operation mode and its influencing factors[J], Commercial Research.(03) , pp.169-174

[12] Martinez-Budria, E, Diaz-Armas,R.,Navarro-Ibanez,M. Ravelo-Mesa,T. 1999. A study of the efficiency of Spanish port authorities using data envelopment analysis [J], International Journal of Transport Economics. 26 (2), pp.237-253

[13] Juan, Yao, Yuliang, Zhuang, 2013. Ownership structure, logistics environment and logistics efficiency in China [J], Research on Financial and Economic Issues. (03), pp.115-122.

[14] Qinmei Wang Cuie Tan 2013 An Empirical Study on the Logistics Efficiency of Xi'an and its influencing Factors [J], Soft Science.27 (05), pp.70-74.

[15] Lei, Wang, Guoliang, Xue, 2014. Analysis of modern logistics efficiency in northern xinjiang based on DEA analysis [J], Resources Science.36 (07), pp.1425-1433. 